UDC 502.3/.7: 502.52

LBC 26

\title{
THE SPATIAL GEOGRAPHICAL ANALYSIS SCANFORVIRUS PROCESSES SHCHERBAKOVSKAYA BEND OF VOLGA
}

\author{
Irina S. Dedova \\ Volgograd State Socio-Pedagogical University, Volgograd, Russian Federation
}

\begin{abstract}
The article provides information about the Genesis and modern relief formation of Shcherbakov bend of the Volga. The role of the lithological-tectonic factor in the isolation and evolution of the external appearance of the bend is emphasized. The characteristic of the tiered relief of the considered territory and transforming its appearance of slope-forming processes: erosion and gravity is given. The role of each in the formation of different types of slopes of Shcherbakov bend is emphasized.
\end{abstract}

Key words: relief, slope, erosion, landslides, talus, bend.

УДК 26

ББК 502.3/.7: 502.52

\section{ПРОСТРАНСТВЕННО-ГЕОГРАФИЧЕСКИЙ АНАЛИЗ СКЛОНОФОРМИРУЮЩИХ ПРОЦЕССОВ ЩЕРБАКОВСКОЙ ИЗЛУЧИНЫ ВОЛГИ}

\author{
Ирина Сергеевна Дедова \\ Волгоградский государственный социально-педагогический университет, г. Волгоград, Российская Федерация
}

Аннотация. В статье приводятся сведения о генезисе и современном рельефообразовании Щербаковской излучины Волги. Подчеркнуга роль литолого-тектонического фактора в обособлении и эволюции внешнего облика излучины. Дана характеристика ярусного рельефа рассматриваемой территории и преобразующих его облик склоноформирующих процессов: эрозионных и гравитационных. Подчеркнута роль каждого в формировании различных типов склонов Щербаковской излучины.

Ключевые слова: рельеф, склон, эрозия, оползни, осыпи, излучина.

Щербаковская излучина Волги - сложное структурное образование, относимое в региональной геоморфологии к долинным излучинам, когда под действием тектоно-литологического фактора деформации подвержены не только речное русло, но и пойменно-терра亏ें совый комплекс. Изгиб русла Волги просле¡ं живается от эрозионного останца Дурман-горы (на границе Волгоградской и Саратовской об\%ิ ластей) до устья р. Добринка на протяжении 85 км течения. Шаг излучины составляет () 65 км, радиус - 13 км. Вершина ее приуроче- на к Столбичам и Щербаковскому сбросу, и в прошлом, формируя аномальный изгиб, речной поток интенсивно разрушал неустойчивые породы, осложненные дизъюнктивной Щербаковского сброса. Поэтому, огибая северное крыло, река имела юго-восточное, а за линией сброса - юго-западное направление течения $[2 ; 4]$.

Геологическое строение этой территории неоднородно. Здесь на дневную поверхность выходят меловые и палеоценовые толщи. Северное крыло излучины сформировано в осад- 
ках сеноманского, туронского, сантонского, кампанского, маастрих-тского ярусов верхнего мела, при этом речной поток размывает сеноманские отложения, кровля которых совпадает с отметками уреза воды. Породы сеноманского и туронского ярусов вскрыты по эрозионным врезам балок водосбора р. Даниловка. Они представлены, песками зеленовато-серыми, кварцево-глауконитовыми [3]. Отложения турона - это мелоподобные мергели, перекрываемые в кровле яруса мягким писчим мелом. В основании турона прослеживается базальный горизонт из галек фосфоритов. Сантонские отложения представлены так называемой «полосатой серией», которая состоит из тонких прослоек серых и темно-серых опок и черных глин [9].

Южное крыло излучины (окрестности с. Нижняя Добринка) сформировано серо-желтыми трещиноватыми опоками сызранского яруса палеоцена и темно-серыми слоистыми глинами маастрихтского яруса верхнего мела. Сызранские и маастрихтские толщи формируют значительную площадь Щербаковской излучины, в том числе ее вершину [8].

Рельеф излучины имеет сложную историю развития, итогом которой является его полигенетичность (сочетание морских и континентальных стадий развития), ярусное строение и формирование равнины типа педимента. Верхний ярус рельефа, также именуемый исходной поверхностью, имеет вид плосковершинных водораздельных массивов и останцов в междуречье Иловли и Волги. Это одни из наиболее высоких плато Волгоградского Поволжья с отметками абсолютной высоты до $+270 \ldots+280$ м [5; 6]. Показатели высот снижаются в южном направлении до $+160 \ldots+180$ м. Исходная поверхность «срезает», в основном, палеогеновые отложения и верхнемеловые (до туронского и сеноманского ярусов). Нижний ярус рельефа расположен на отметках $+130 \ldots+150$ м. К северу от с. Щербаковка Волга, по-видимому, разрушила нижнее плато, и на участке с. Белогорка с. Нижняя Банновка непосредственно к Волге обрывами в 200-250 м «спускается» верхний ярус [10; 17]. Последний формировался в пределах Волжского Правобережья с доплиоценового времени, а амплитуда его тектонического поднятия составила около 400 м [11;
15]. Водораздельные поверхности отделены от нижнего яруса уступом и склоном транзита, покрытого у основания делювиальным «плащом» мощностью до 20 м.

Нижний ярус - это полигенетическая аккумулятивно-денудационная поверхность, формирование которой связано с «саванновой планацией» плиоцена, доакчагыльским эрозионным циклом и акчагыльской трансгрессией Палео-Каспия [7]. В виде структурной ступени отмечается наложенная на нижний ярус абразионно-аккумулятивная хвалынская терраса верхнего плейстоцена, прослеженная по территории Волгоградского Поволжья в пунктах с. Щербаковка, с. Антиповка, ст. Суводская, г. Волгоград. Мощность хвалынских отложений в пределах рассматриваемой территории небольшая, от нескольких десятков сантиметров до нескольких метров, они прослеживаются на абсолютной высоте $+40 \ldots+50$ м и представлены слоистыми «шоколадными» глинами с прослоями кварцевого алеврита.

Внешний облик рельефа территории обусловлен сложной морфоструктурной организацией (Приволжская моноклиналь), а также разнообразием рельефообразующих процессов, формирующих сложные морфодинамические системы типа «междуречье - уступ - склон транзита- педимент - аккумулятивная равнина» [18]. Итогом их коэволюции является выработка профиля равновесия склонов и формирование педимента [12; 21-24]. Важная роль в этих событиях принадлежит склоноформирующим процессам, среди которых выделяются плосткостной смыв, эрозионный размыв, гравитационные процессы. Характер их распространения зависит от уклона поверхности, ее геологического сложения, ее площади и т. д. Так, плоскостной смыв проявляется в приводораздельной части склона с величиной уклона до 0 48' [20], эрозионный размыв активен при крутизне поверхности более $1^{\circ}$; гравитационные процессы тесным образом зависят от физических характеристик горных пород, слагающих склон; его высоты, крутизны и т. д.

Пространственный анализ склоноформирующих процессов Щербаковской излучины позволяет выделить ряд геоморфологических зон, отличающиеся их набором и интенсивностью проявления. Так, плоскостной смыв ти- 
пичен для приводораздельных слабонаклонных поверхностей ярусов рельефа, активно протекающая эрозия и гравитационные процессы - для склона транзита, наклонных аккумулятивных поверхностей у основания склона, а также для морской хвалынской абразионно-аккумулятивной террасы. Рассмотрим их более подробно.

Эрозионные процессы являются наиболее презентабельными на территории Щербаковской излучины. Здесь представлены как следы древних эрозионных процессов, так и современных. Среди древних эрозионных форм известны долины малых рек (Щербаковки, Галки, Даниловки и др.) и делли, среди современных - овраги и промоины (рис. 1). Пространственно они относятся к двум водосборам - Волжскому и Донскому.

Балочные и речные системы, впадающие в Волгоградское водохранилище, отличаются большей крутизной продольного профиля. Показатель падения русел и тальвегов составляет от 7 м/км (р. Галка) до 30-40 м/км (притоки б. Даниловка, Мостовой Овраг, Сергичев Овраг и др.). Для долин Донского водосбора (притоки р. Иловли) отмечается сгла- женность профиля, а показатель падения русла сокращается до 3-5 м/км, что обусловлено меньшей крутизной донского склона Приволжской возвышенности. Балки и малые реки имеют широкие долины и связаны перехватами с эрозионными системами Волжского бассейна. Они неглубоко врезаны (глубина базиса эрозии - 20-40 м).

Практически для всех рассмотренных эрозионных систем Щербаковской излучины отмечается значительная протяженность. Она варьирует от нескольких сот метров у небольших промоин до 15-25 км у древних долин и балок (например, протяженность р. Галка 15 км, Липового Оврага 20 км, Щербаковки и Даниловки - около 18 км) [10]. Малую длину (менее 1 км) имеют промоины, ложбины и прочие формы первого, реже второго порядка, более 1 км - эрозионные формы второго и третьего порядка, более 5 км - древние балочные и речные системы, обладающие порядком не ниже третьего. Установлено, что порядок связан с площадью водосбора, и чем больше ее показатель, тем выше порядок $($ К кор $=0,89)$ (см. рис. 2). Для правобережья p. Волги была установлена следующая кар-

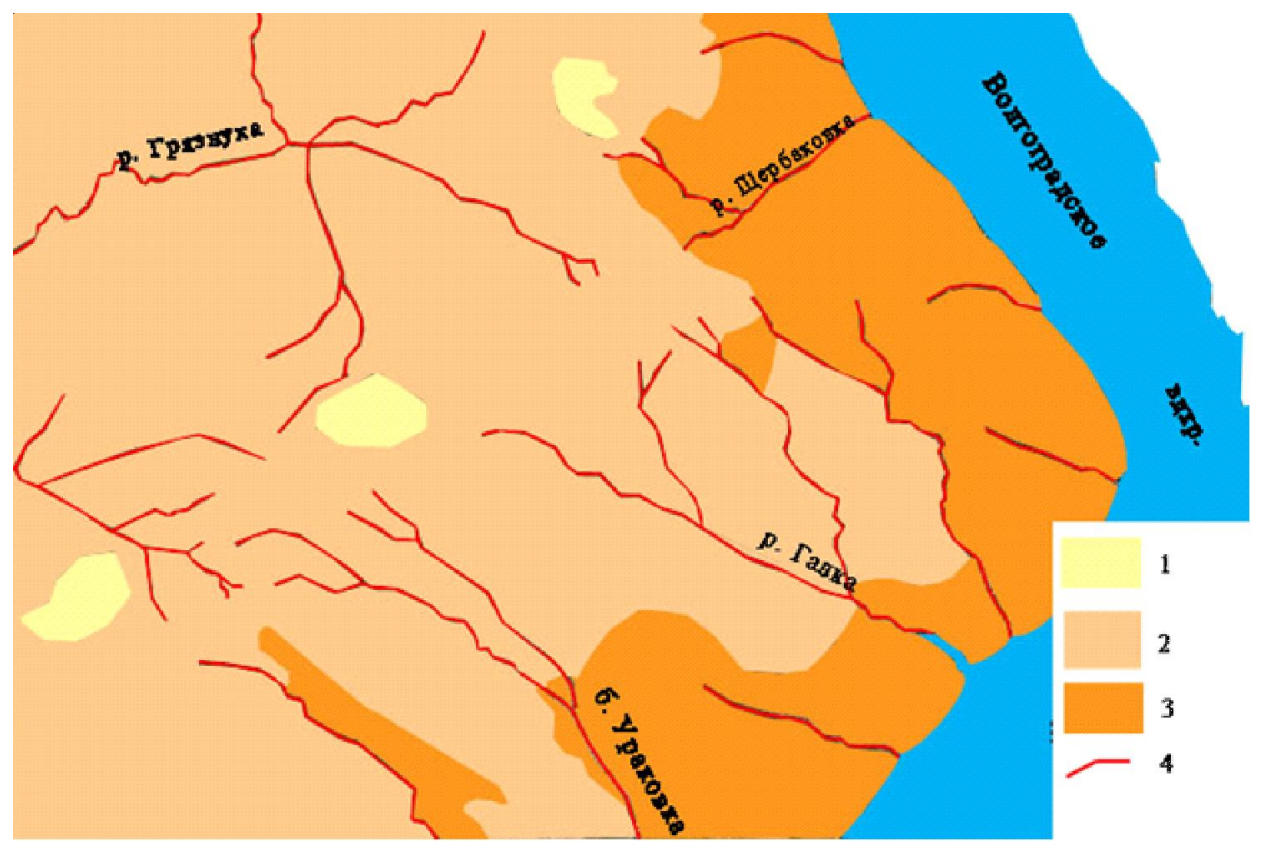

Рис. 1. Эрозионные процессы в пределах Щербаковской излучины

1 - зона отсутствия эрозии; 2 - зона древнего эрозионного размыва;

3 - зона развития современной эрозии; 4 - эрозионные системы

Примечание. Составлено автором по данным дешифрирования космоснимков сайта www.maps.google.com. 


\section{ГЕОГРАФИЯ И ГЕОИНФОРМАТИКА}

тина: долины первого порядка имеют показатель площади водосбора около 2 км$^{2}$, второго порядка - 2-6 км ${ }^{2}$, третьего - 6-19 км ${ }^{2}$, четвертого - 20-50 км ${ }^{2}$ пятого - более 50 км $^{2}$ (по картам масштаба 1:200000).

Древние эрозионные формы обладают значительной глубиной вреза (до 80-100 м, а некоторые - до 200 м), а короткие ветвящиеся овраги, промоины и делли, приуроченные к верхним частям склонов водосборов, - небольшой (5-15 м). Разработанные эрозионные долины обладают также и значительной шириной со средним показателем в верховьях 83 м, в средней части 274 м, в устье 550 м и суммарным примерно в 300 м.

Отличительная особенность эрозионных систем Щербаковской излучины - повсеместное вскрытие водоносного горизонта и формирование ложбин постоянных водотоков, а также покрытость верховий и склонов лесом. Площадь леса в верховьях составляет от 1 км$^{2}$ до 9 км² $^{2}$ более покрыты лесом инсолируемые склоны, чем теневые. Для балок и долин, впадающих в водохранилище, характерно затопление устьев и образование нешироких ингрессионных заливов, длиной от 500 м до 2 км.

Таким образом, в пределах рассматриваемой территории отмечается многообразие эрозионных форм, однако в площадном отношении превалируют балки и речные долины. Причина этого - облеснение верховий, склонов и тальвегов, тормозящих развитие эрозионной системы, вскрытие водоносного горизонта. Зона современной эрозии в основном приурочена к окрестностям населенных пунктов, а также к берегу водохранилища; это главным образом поверхность снижения и хвалынская терраса.
Исходя из критерия выделенных нами геоморфологических зон для верхнего яруса рельефа, представляющего собой плосковершинную поверхность, отмечается отсутствие эрозии, $\mathrm{K}_{\text {эр }}$ составляет 0 км/км ${ }^{2}$; это зона, где вследствие геолого-геоморфологических причин эрозия не возможна. Для уступа, переходящего в склон транзита, характерны активно протекающие процессы эрозионного расчленения, преобладают малые по протяженности промоины, овраги, а также древние формы делли; здесь отмечается $\mathrm{K}_{\text {эр }}=1,4$ км/км². Для нижнего яруса рельефа показатели эрозионного расчленения составляют около 3,2 км/км². Это наиболее пораженная овражно-балочной сетью и долинами малых рек зона. Наконец, поверхность хвалынской террасы, занимающей наиболее низкий гипсометрический уровень, обладает показателем $\mathrm{K}_{\text {эр }}$ до 1,2 км/км²; причина - отсутствие естественных уклонов и молодость геоморфологического элемента [19].

Таким образом, наиболее высокие показатели эрозионного расчленения излучины отмечены для поверхности нижнего плато и «уступа», что обусловлено крутизной склонов (до $30^{\circ}$ ), а также наклоном пластов коренных пород к Волге $\left(0,2-2,5^{\circ}\right)$ (см. рис. 3).

Плотность малых эрозионных форм, представленных здесь ветвящимися промоинами и молодыми оврагами, а также деллями, значительными показателями. Они отсутствуют в пределах исходной поверхности, но на поверхности уступа и склона тран-зита их показатель возрастает до 2-5 шт./км². Наиболее расчленены ими нижний ярус и хвалынская терраса. Здесь средний показатель возрастает до более чем 5 шт./км ${ }^{2}$. Балочное звено развито менее. Это обусловлено современной активи-

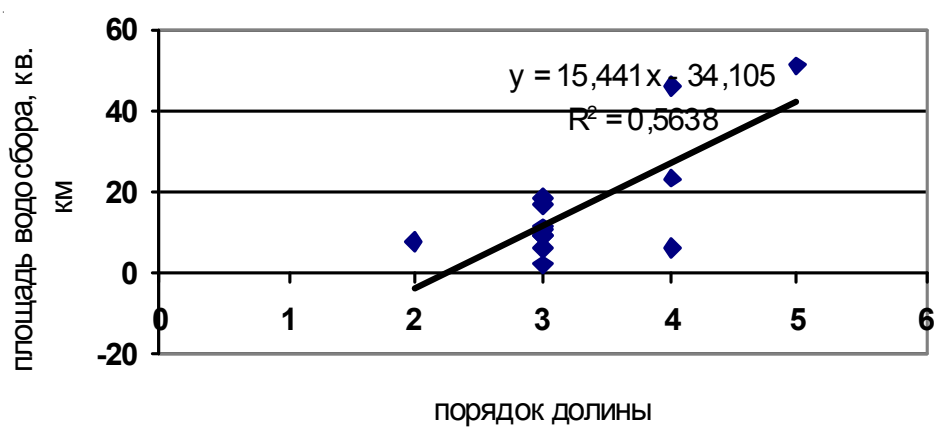

Рис. 2. Зависимость площади водосбора от порядка долины в пределах Щербаковской излучины 
зацией эрозии и переходом небольших по размеру суходолов и лощин в разряд растущих форм. Так, поверхность уступа и склона транзита - зона развития их верховьев, показатель плотности здесь менее 1 шт./км². Более развиты поросшие лесом лощины и балки в пределах нижнего яруса рельефа и поверхности морской террасы (до 1-2 шт./км²). Наибольшая их концентрация отмечается в пределах водосбора р. Грязнухи, где плотность составляет более 3,5 шт./км². Здесь широко развита древняя эрозионная сеть, представленная суходольным, лощинным и балочным звеном.

Итак, Щербаковская излучина может быть отнесена к территориям с интенсивным эрозионным расчленением. Основными факторами развития густого эрозионного расчленения являются геологическое сложение местности легко размываемыми терригенными породами, значительный подъем территории за олигоцен-четвертичное время, ярусный рельеф. Главной ареной для развития эрозионных форм служит поверхность нижнего яру$\mathrm{ca}$, имеющего полигенетический характер, a также нижняя часть уступа и обломочный склон. При этом на зону отсутствия денудации с крутизной поверхности менее $0^{\circ} 38$, приходится около $4 \%$ от исследуемой территории, зону слабой денудации или микроручейкового размыва с крутизной поверхности $1,5^{\circ}-$ $2,36^{\circ}$ - около $4 \%$, зону сильной денудации более $92 \%$. К первой категории относится поверхность верхнего плато, ко второй - прибровочные поверхности верхнего яруса, к третьей - уступ, обломочный склон и нижний ярус с прислоненной к нему хвалынской террасой.
Гравитационные процессы в пределах Щербаковской излучины формируют осыпи и оползни, причем среди последних также отмечаются как древние, так и современные.

Среди древних оползней, образовавшихся при ином базисе эрозии и уровне абразии, выделяются открытые и погребенные. Открытые оползни представлены крупными грядами и ничем, кроме почвы, не покрытые. Погребенные оползни встречены в разрезах геологических обнажений по бортам эрозионных врезов оврагов, балок, долин малых рек, где деляпсий перекрыт более молодыми отложениями. Щербаковские оползни по глубине захвата смещающихся пород относятся к группе нормальных или истинных оползней, классам глубоких и поверхностных. Глубокие оползни образуются с нарушением общего равновесия склона в целом или локального равновесия его значительной части, а поверхностные вызваны нарушением частного равновесия покровных образований на склоне. Глубокие оползни развиваются по поверхности маастрихтских глин и сызранских опок, по наклонным поверхностям ослабления, а поверхностные - в покровном делювии и имеют чаще всего статус оплывин.

По механизму оползневого процесса оползни Щербаковской излучины - это оползни сдвига I группы, развитые в маастрихтских глинах и сызранских опоках. При этом сдвиг блоков происходит по горизонтальной поверхности в глинистом слое вследствие развития процесса ползучести, переходящего в срез [14; 16]. Щербаковские оползни сдвига, как современные, так и древние, возникают в

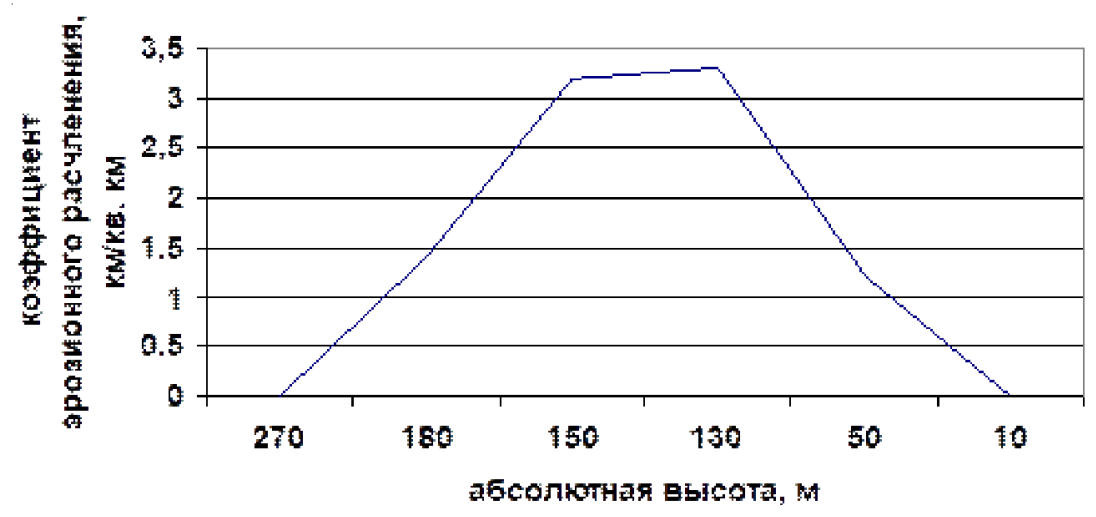

Рис. 3. Изменение густоты эрозионного расчленения при удалении от водораздельной линии в Щербаковской излучине 
слабо наклонных комплексах пород, в пределах которых четко выделяются основные деформирующиеся горизонты.

Отмеченные в пределах рассматриваемой территории малые снивелированные и современные оползни можно отнести к оползням-потокам или оплывинам. Они развиваются на поверхности, где оплыванием захватывается толща породы всего лишь на 0,31,5 м. Причиной его служит избыточное увлажнение верхнего слоя грунта, иногда только почвы. Оплывинные склоны отличаются от других типов склонов микроступенчато-стью. Так, на склонах р. Щербаковки в связи с выпасом скота оплывание возникает без особо сильного увлажнения при слабо пластичном состоянии грунта. Перемещаясь по террасовидным площадкам шириной в несколько десятков сантиметров, животные временно увеличивают нагрузку на грунт, что способствует его смещению, в результате формируется микрогофрировка склона.

Помимо оползневого процесса, склоны в пределах Щербаковской излучины покрыты осыпями, местами формирующие обвалы. Размер обломков в пределах последних составляет до 1 м. В основном осыпи сформированы коллювием обрушения, состоящим из плитчатых обломков глин и опок размером до $15 \times 15$ см. Коллювий обрушения формирует сомкнутые шлейфы, прислоненные к нижним частям склонов эрозионных форм на значительном их протяжении, а также к оползневым телам. Благоприятны для развития осыпей и склоны, обладающие крутизной до $60^{\circ}$ (то есть более $30^{\circ}$ ). Это все склоны в пределах рассматриваемой территории, и, следовательно, они обладают значительным потенциалом для развития осыпных явлений. Осыпи здесь являются долго живущими, то есть постоянно наращивают свой объем.

Таким образом, на территории Щербаковской излучины развиты два типа гравитационных процессов: оползневой и осыпной. Оползни имеют сложное, ступенчато-блоковое, строение и представлены как современными, инспирированными абразией склонов Приволжской возвышенности водохранилищем, так и древними, образовавшимися в хвалынский век. Также отмечаются такие интересные формы как оплывины, создающие микрогофрировку склонов. Развитие оползневого процесса связано с массивом трещиноватых опок и пластичных глин, крутыми склонами эрозионных систем, в том числе и долины р. Волга, а также гидрогеологическими особенностями и наклоном пластов к Волге под углом 2-4 ${ }^{\circ}$.

Осыпи, также как и оползни, развиты на неустойчивых склонах со значительной крутизной. Породы, их слагающие, разрушаются физическим выветриванием, поэтому осыпи плащеобразно развиты вдоль склонов речных долин, оврагов, оползневых блоков. Эволюция осыпного процесса из-за существенной разницы между показателями крутизны склона и угла внутреннего трения долговременна.

Итак, ярусный рельеф Щербаковской излучины в совокупности с литолого-структурными и биоклиматическими условиями обусловил развитие двух типов склоновых процессов: флювиально-эрозионных и гравитационных. По времени проявления они дифференцируются на доголоценовые, или древние, и голоценовые (современные). Особенностью эрозионного процесса является зональность его развития. Было выделено три геоморфологических зоны, которые «привязаны» к ярусам рельефа. Они отличаются по показателям плотности эрозионных форм и $\mathrm{K}_{\text {эр }}$. Гравитационные процессы отмечаются повсеместным развитием. Они приводят к выработке профилей склонов и сводятся к оползневому и осыпному процессам. Осыпи, развитые в различных породах, имеют и различное время выработки профиля. Оползни инспирированы древней морской и современной абразией, а также гидрогеологией местности.

Склоновые процессы в течение времени своего проявления приводили к преобразованию ярусного рельефа, наращиванию объема педимента и сохранению уступов, поэтому в процессе эволюции склоны претерпели неоднократную литодинамическую сукцессию, приводящую к переработке их профиля, выполаживанию и др. [1; 18]. Поэтому, опираясь на многочисленные классификации, их можно охарактеризовать следующим образом [13].

1. По форме. Склоны верхнего яруса можно отнести к вогнутым и вогнуто - ступенчатым на Дону, а на Волге - к вогнутым; 
долинно-балочная сеть обладает прямолинейными, выпуклыми, выпукло-вогнутыми и ступенчатыми склонами.

2. По генезису. Склоны верхнего яруса являются свободными, долинно-балочной сети и нижнего яруса, обрывающиеся к речным системам, - подпертыми. У верхнего яруса, балок и оврагов склоны денудационные, в пределах Столбичей - тектонические, вдоль берега Волги - это оползневые, у молодых эрозионных форм склоны осыпные.

3. По наличию рыхлых отложений. Участки педимента, а также долинные и балочные склоны с выработанным профилем обладают рыхлыми четвертичными отложениями, в то время как участки склонов молодых эрозионных форм лишены их.

4. По крутизне. Педимент относится к очень пологим склонам (крутизной менее $5^{\circ}$ ), склоны верхнего яруса - к крутым и средним по крутизне (более $35^{\circ}$ ), склоны балок - к пологим $\left(5-15^{\circ}\right)$ и средним $\left(15-35^{\circ}\right)$, оврагов, речных долин - Щербаковки, Даниловки к крутым.

Почти все склоны являются экзогенными, которые по механизму формирования делятся на гравитационные (по оврагам, круто врезанным - осыпные), склоны блоковых движений или оползневые и склоны смыва или делювиальные.

\section{СПИСОК ЛИТЕРАТУРЫ}

1. Агафонов, Б. П. Склоны как сложные морфолитодинамические системы / Б. П. Агафонов // Проблемы методологии геоморфологии. - Новосибирск, 1989. - С. 99-103.

2. Брылев, В. А. Происхождение и возраст поверхностей выравнивания Волгоградского Поволжья / В. А. Брылев // Вопросы географии Нижнего Поволжья - Волгоград, 1973. - С. 27-36.

3. Брылев, В. А. Этапность и цикличность морфогенеза окраин платформ (на примере юговостока Европейской части СССР) : автореф. дис. .. д-ра геогр. наук / Брылев Виктор Андреевич. - М., 1988. -39 c.

4. Брылев, В. А. Развитие и современное состояние эрозионной сети на юго-востоке Европейской части России / В. А. Брылев // Геоморфология. -1997 . - № 4. - С. 51-53.

5. Брылев, В. А. Эволюционная геоморфология юго-востока Русской равнины / В. А. Брылев. Волгоград : Перемена, 2006. - 350 с.
6. Брылев, В. А. Природа Щербаковской излучины: рукописн. отчет комплексной экспедиции /под общ. ред. В. А. Брылева. - Волгоград : ВГПИ, 1982. $-76 \mathrm{c}$.

7. Брылев, В. А. Новый разрез у г. Камышин и его палеогеографическое значение / В. А. Брылев, Н. А. Самусь // Доклады АН СССР. - 1984. - Т. 277, № 6. - С. 1453-1454.

8. Брылев, В. А. Формирование больших коренных излучин Волго-Донского водораздела (в пределах Волгоградской области) / В. А. Брылев, И. С. Трофимова // Геоморфология. - 2008. - № 3.C. $77-85$.

9. Геология СССР. Т. 46: Ростовская, Волгоградская, Астраханская области Калмыцкая АССР / под ред. А. В. Белова. - М. : Недра, 1970. - 667 с.

10. Геоморфология Волгоградской области / В. А. Брылев [и др.]. - М. : Планета, 2017. - 224 с.

11. Горелов, С. К. Геоморфология и новейшая тектоника Правобережья Нижней Волги / С. К. Горелов // Труды Институга Географии. - М., 1957. Вып. 19. - 140 с.

12. Дедков, А. П. Поверхности снижения и формирование ярусности рельефа / А. П. Дедков, Г. П. Бутаков, Ю. В. Бабанов // Развитие склонов и выравнивание рельефа. - Казань, 1974. C. 3-37.

13. Дедова, И. С. Типизация склонов Волгоградской области / И. С. Дедова // Вопросы краеведения : материалы XXVIII Волгогр. обл. краевед. чтений. - Волгоград, 2017. - С. 184-189.

14. Емельянова, Е. П. Основные закономерности оползневых процессов / Е. П. Емельянова. М. : Недра, 1972. -308 c.

15. Методика изучения неотектоники и морфоструктура Нижнего Поволжья / под ред. А. В. Цыганкова. - Волгоград : Нижне-Волж. кн. изд-во, 1971. $-255 \mathrm{c}$.

16. Оползни Среднего и Нижнего Поволжья и меры борьбы с ними / под ред. Е. В. Милановского, М. П. Семенова. - М. ; Л. : Главная редакция строительной литературы, $1935 .-252$ c.

17. Природные условия и ресурсы Волгоградской области / под ред. В. А. Брылева. - Волгоград : Перемена, 1995. - 264 с.

18. Тимофеев, Д. А. Принципы типизации геоморфологических процессов / Д. А. Тимофеев // Геоморфология. - 2004. - № 4. - С. 16-20.

19. Трофимова, И. С. Формирование больших коренных излучин Волги и Дона (на примере Волгоградской области) : автореф. дис. ... канд. геогр. наук / Трофимова Ирина Сергеевна. - М. : Ин-т Географии РАН, 2008. -24 с.

20. Хортон, Р. Е. Эрозионное развитие рек и водосборных бассейнов / Р. Е. Хортон. - М. ; Л. : Изд-во иностр. лит-ры, 1948. - 158 с. 
21. Birot, P. Etude quantitative des processes erosive agissant sur les versants / P. Birot // Geomorphol. - 1970. - № 9. - P. 123-135.

22. Carson, M. A. The existence of threshold hillslopes in the denuda-tion of the landscape / M. A. Carson, D. J. Petley // Trans. inst. Brit. Geogr. London. - 1970. - № 42. - P. 3-24.

23. Davis, W. M. The Geographical cycle / W. M. Davis // Geogr. Journ. - 1899. - Vol. 14, № 5 . -24 p.

24. Kramer, L. A. Erosions equations predict land slope development / L. A. Kramer, L. D. Meyer //Z. Agriculturel Engineering. - 1969. - № 50.-P. 45-65.

\section{REFERENCES}

1. Agafonov B.P. Sklony kak slozhnyye morfolitodinamicheskiye sistemy. Problemy metodologii geomorfologii. Novosibirsk, 1989, pp. 99-103.

2. Brylev V.A. Proiskhozhdeniye i vozrast poverkhnostey vyravnivaniya Vol-gogradskogo Povolzhia. Voprosy geografii Nizhnego Povolzhia, Volgograd, 1973, pp. 27-36.

3. Brylev V.A. Etapnost $i$ tsiklichnost morfogeneza okrain platform (na primere yugovostoka Evropeyskoy chasti SSSR) : avtoref. diss. ... d-ra geogr. nauk. Moscow, 1988. 39 p.

4. Brylev V.A. Razvitiye i sovremennoye sostoyaniye erozionnoy seti na yugo-vostoke Evropeyskoy chasti Rossii. Geomorfologiya, 1997, no. 4, pp. 51-53.

5. Brylev V.A. Evolyutsionnaya geomorfologiya yugo-vostoka Russkoy ravniny. Volgograd, Peremena, 2006. 350 p.

6. Brylev V.A. Priroda Shcherbakovskoy izluchiny: rukopisn. otchet kompleksnoy ekspeditsii. Volgograd, VGPI, 1982.76 p.

7. Brylev V.A. Novyy razrez u g. Kamyshin i ego paleogeograficheskoye znacheniye. Doklady AN SSSR, 1984, vol. 277, no. 6, pp. 1453-1454.

8. Brylev V.A. Formirovaniye bolshikh korennykh izluchin Volgo-Donskogo vodorazdela (v predelakh Volgogradskoy oblasti). Geomorfologiya, 2008, no. 3, pp. 77-85.

9. Belov A.V. ed. Geologiya SSSR. T. 46: Rostovskaya. Volgogradskaya. Astrakhanskaya oblasti Kalmytskaya ASSR. Moscow, Nedra, 1970. $667 \mathrm{p}$.

10. Brylev V.A. et. al. Geomorfologiya Volgogradskoy oblasti. Moscow, Planeta, 2017. 224 p.

11. Gorelov S.K. Geomorfologiya i noveyshaya tektonika Pravoberezhia Nizhney Volgi. Trudy Instituta Geografii, Moscow, 1957, iss. 19. 140 p.

12. Dedkov A.P. Poverkhnosti snizheniya i formirovaniye yarusnosti relyefa. Razvitiye sklonov $i$ vyravnivaniye relyefa. Kazan, 1974, pp. 3-37.

13. Dedova I.S. Tipizatsiya sklonov Volgogradskoy oblasti. Voprosy krayevedeniya: materialy XXVIII Volgogradskikh oblastnykh krayevedcheskikh chteniy. Volgograd, 2017, pp. 184-189.

14. Emelianova E.P. Osnovnyye zakonomernosti opolznevykh protsessov. Moscow, Nedra, 1972. 308 p.

15. Tsygankov A.V. Metodika izucheniya neotektoniki i morfostruktura Nizhnego Povolzhia. Volgograd, Nizhne-Volzh. kn. izd-vo, 1971. 255 p.

16. Milanovskiy E.V., Semenov M.P. eds. Opolzni Srednego i Nizhnego Povolzhia i mery borby s nimi. Moscow, Leningrad, Glavnaya redaktsiya stroitelnoy literatury, 1935. $252 \mathrm{p}$.

17. Brylev V.A. Prirodnyye usloviya i resursy Volgogradskoy oblasti. Volgograd, Peremena, 1995. $264 \mathrm{p}$.

18. Timofeyev D.A. Printsipy tipizatsii geomorfologicheskikh protsessov. Geomorfologiya, 2004, no. 4, pp. 16-20.

19. Trofimova I.S. Formirovaniye bolshikh korennykh izluchin Volgi i Dona (na primere Volgogradskoy oblasti) : avtoreferat diss. ... kand. geogr. nauk. Moscow, Institut Geografii RAN, 2008. 24 p.

20. Khorton R.E. Erozionnoye razvitiye rek $i$ vodosbornykh basseynov. Moscow, Leningrad, Izdvo inostr. lit-ry, 1948. $158 \mathrm{p}$.

21. Birot P. Etude quantitative des processes erosive agissant sur les versants. Geomorphol, 1970, no. 9, pp. 123-135.

22. Carson M.A. The existence of threshold hillslopes in the denudation of the landscape. Trans. inst. Brit. Geogr. London, 1970, no. 42, pp. 3-24.

23. Davis W.M. The Geographical cycle. Geogr. Journ, 1899, vol. 14, no. 5. 24 p.

24. Kramer L.A. Erosions equations predict land slope development. Z. Agriculturel Engineering, 1969, no. 50 , pp. $45-65$. 
И.С. Дедова. Пространственно-географический анализ склоноформирующих процессов

\section{Information about the Author}

Irina S. Dedova, Candidate of Sciences (Geography), Associate Professor, Department of Geography, geoecology and methods of teaching geography, Volgograd State Socio-Pedagogical University, prosp. im. V.I. Lenina, 27, 400005 Volgograd, Russian Federation, itrofimova@yandex.ru.

\section{Информация об авторе}

Ирина Сергеевна Дедова, кандидат географических наук, доцент кафедры географии, геоэкологии и методики преподавания географии, Волгоградский государственный социальнопедагогический университет, просп. им. В.И. Ленина, 27, 400005 г. Волгоград, Российская Федерация, itrofimova@yandex.ru. 